\title{
Análise das questões sobre radioatividade no Exame Nacional do Ensino Médio -
} ENEM

Analysis of radioactivity in the brazilian high school examination - ENEM

Lucas dos Santos Fernandes ${ }^{1}$

Angela Fernandes Campos $^{2}$

\section{Resumo}

O presente estudo buscou identificar as características das questões do ENEM referentes ao tema radioatividade pertencente à área de Ciências da Natureza e suas Tecnologias. A análise se deu a partir das seguintes categorias: tipo de questão, contextualização, interdisciplinaridade, recursos visuais, eixo cognitivo e aplicação da radioatividade. Os resultados apontaram o predomínio de questões qualitativas, contextualizadas com o meio ambiente, interdisciplinares, envolvendo a Química e a Biologia, pertencentes ao eixo cognitivo da compreensão dos fenômenos e com aplicação da radioatividade na geração de energia nuclear. $O$ presente estudo contribui para o esclarecimento de como o tema radioatividade vem sendo abordado no ENEM ao longo das edições desse exame, para professores no planejamento de suas aulas sobre radioatividade e para o estudo desse tema pelos estudantes.

Palavras chave: ENEM; questões; radioatividade.

\section{Abstract}

The present study sought to identify the characteristics of ENEM questions regarding radioactivity in the area of Natural Sciences and their Technologies. Analysis involved the following categories: type of question, contextualization, interdisciplinarity, visual resources, cognitive axis and application of radioactivity. The results show the predominance of qualitative questions, contextualized with the environment, interdisciplinary, involving Chemistry and Biology, belonging to the cognitive axis of phenomenon comprehension, with applications of radioactivity in nuclear energy generation. The present investigation contributed by clarifying how the issue of radioactivity has been applied in the ENEM during the different editions of this examination, in addition to helping professors plan their classes on radioactivity and students studying this subject.

Keywords: ENEM; questions; radioactivity.

\footnotetext{
${ }^{1}$ lucas.fernandes@univasf.edu.br

2 afernandescampos@gmail.com
} 


\section{Introdução}

O Exame Nacional do Ensino Médio (ENEM) existe desde 1998 e, atualmente, é o maior instrumento de avaliação educacional do Brasil. O resultado da avaliação do ENEM pode ser utilizado para várias finalidades, tais como a certificação de conclusão do Ensino Médio e a inserção no Ensino Superior ou Técnico em instituições públicas e particulares. Os conteúdos que constam nas provas do ENEM são definidos a partir de uma Matriz de Referência (BRASIL, 2009), que também apresenta competências, habilidades e eixos cognitivos a serem contemplados nas questões.

Segundo Ramalho e Nuñez (2013) o ENEM surgiu a princípio, como um teste optativo, no entanto, em 2009, com a política de sistematização e qualificação da educação básica e a educação superior com ações mais inclusivas e democráticas oportunizadas pelo MEC, o ENEM passou a funcionar com dois grandes objetivos: "induzir referências para potencializar a reestruturação dos currículos do ensino médio, apostando na elevação da qualidade desse nivel de ensino, e criar um processo unificado para selecionar estudantes para as universidades de elevada concorrência em seus cursos e também os ganhos de uma seleção nos moldes propostos"(p.8). Sob essa perspectiva, a avaliação instituída pelo ENEM possui uma forte articulação com os documentos oficiais que regulamentam o Ensino Médio, como as Orientações Curriculares Nacionais (OCEM/2006) e os Parâmetros Curriculares Nacionais para o Ensino Médio (PCNEM/1999). Esses documentos orientam para uma proposta de trabalho em sala de aula que se distancia do modelo de ensino com ênfase na transmissão-recepção de conteúdos (tradicional). Os dois pilares fundamentais para o ensino presentes nos PCNEM são a interdisciplinaridade e contextualização, tidos como estratégias potenciais de articulação de conteúdos e significados dos conceitos respectivamente, que devem ser utilizados para responder a situações problemáticas inseridas em diversos contextos da ciência, tecnologia e sociedade. Assim, os PCNEM orientam:

[...] conteúdos e conceitos das Ciências sejam abordados de forma contextualizada e interdisciplinar a partir de temas e/ou situaçõesproblema, iniciando pelas mais próximas dos alunos até as mais distantes, na perspectiva dos estudantes desenvolverem competências que os capacitem a refletir sobre o papel das Ciências e das técnicas na sociedade (BRASIL, 1999).

No que se refere à Química, essa disciplina está inserida na área de Ciências da Natureza e suas Tecnologias e apresenta uma série de conteúdos que podem ser abordados na perspectiva de situações-problema. Entre os conteúdos de Química, o tema radioatividade surge em dois tópicos: (i)- transformações químicas e energia; (ii)- energias químicas no cotidiano. A radioatividade consiste em um fenômeno natural que corresponde à emissão de partículas e/ou radiação por átomos que apresentam núcleos instáveis. Ao longo do tempo, os fenômenos radioativos passaram a ser controlados e produzidos artificialmente com fins determinados em benefício da sociedade, como por exemplo: diagnósticos por imagem, esterilização de materiais cirúrgicos, produção de energia nuclear, radioterapia, entre outros. Apesar de ser considerado um fenômeno pouco comum, Aquino e Aquino (2012) afirmam que é impossível não entrar em contato com radiações oriundas de processos radioativos, devido ao contato com isótopos radioativos que existem em proporções mínimas na água, no solo e no ar. 
O ensino do tema radioatividade envolve conteúdos complexos e abstratos da Química, tais como: estrutura atômica, propriedades periódicas e radiações eletromagnéticas. As dificuldades de aprendizagem da radioatividade por parte dos estudantes em diferentes níveis de ensino é retratada na literatura (SILVA et al, 2013; TEKIN e NAKIBOGLU, 2006) e, por isso, podem ter implicação no surgimento de concepções alternativas. Segundo Boo (1998) as concepções alternativas são ideias dos estudantes que estão em desacordo com o que é aceito atualmente pela comunidade científica. Nesse sentido, possibilitar um ensino com os fundamentos teórico-metodológicos retratados nos PCNEM e presentes no ENEM pode contribuir para minimizar os problemas de aprendizagem apontados na literatura sobre o tema radioatividade. Vários conceitos relacionados a radioatividade podem ser melhor compreendidos a partir da compreensão de alguns fenômenos, tais como: datação de artefatos arqueológicos, geração de energia nuclear e processos de fusão e fissão nuclear. $O$ ensino de radioatividade a partir desses fenômenos apresenta potencial significativo para o estabelecimento de relações entre a Ciência, a Tecnologia e a Sociedade (CTS) (SANTOS e SCHNETZLER, 2010). Esse tema também, pode ser abordado no contexto escolar a partir de várias estratégias de ensino, em consonância com o que está colocado nas Orientações Curriculares Nacionais (2006) e com o que é exigido em termos de avaliação pelo ENEM, nesse sentido, vale citar algumas experiências didático-pedagógicas exitosas, tais como: utilização de Flexquests (VASCONCELOS e LEÃO, 2012) e resolução de situação-problema (SILVA, et al, 2014). É importante enfatizar que os aspectos ambientais são intrínsecos ao estudo da radioatividade, tendo em vista que, vários episódios negativos de catástrofes ambientais relacionados a fenômenos radioativos foram disseminados pela mídia nos últimos anos (Chernobyl, 1986; Goiânia, 1987; Fukushima, 2011), por isso, podem se constituir como possibilidades de articulação entre disciplinas como Química e Biologia, Química e Física, fomentando, dessa forma, ações voltadas à interdisciplinaridade.

A partir do exposto sobre o ENEM e a temática radioatividade, este estudo possui o objetivo de analisar as questões do ENEM, buscando identificar características dos enunciados que possam auxiliar na compreensão de como esse conteúdo vem sendo abordado ao longo das edições desse exame. A seguir são descritos os procedimentos metodológicos utilizados nesta pesquisa. Os subtítulos principais (introdução, referencial teórico, etc.)

\section{Metodologia}

Esta investigação consiste em uma Pesquisa documental (GIL, 2010), na qual o corpus de análise foi as provas do ENEM realizadas desde 1998. Este estudo pode ser classificado como qualitativo, tendo em vista que, a análise de dados foi realizada de forma descritiva e interpretativa (LUDKE e ANDRÉ, 2013

\section{Coleta de Dados}


A coleta de dados foi realizada a partir do site do Instituto Nacional de Estudos e Pesquisas Educacionais Anísio Teixeira ${ }^{3}$. Foram selecionadas as provas do ENEM da área de Ciências da Natureza e suas Tecnologias no período de 1998 a 2015, em seguida, foram identificadas e analisadas as questões relacionadas ao tema radioatividade. Também foram analisadas as provas aplicadas das edições em que o ENEM teve dupla aplicação devido a dificuldades operacionais.

\section{Categorização}

As categorias utilizadas para analisar as questões identificadas foram: tipo de resposta, contextualização, interdisciplinaridade, recursos visuais, eixo cognitivo e aplicação da radioatividade (Figura 1). O estabelecimento das categorias de análise teve como referenciais teóricos os estudos de Ramalho e Nuñez (2013), Uehara e Núñez (2011), Marcelino-Júnior (2013) e a Matriz de Referência para o ENEM (BRASIL, 2009).

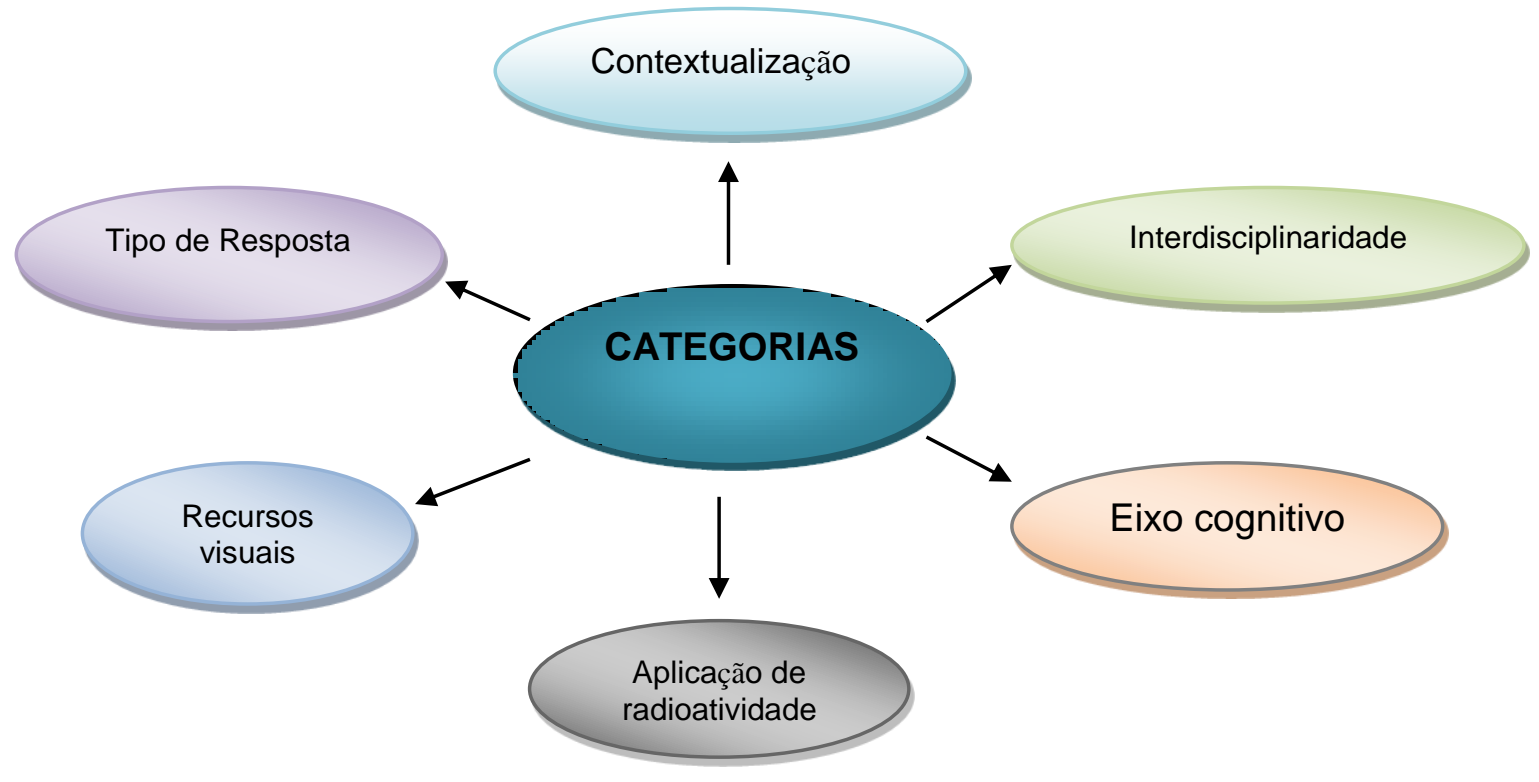

Figura 1. Categorias estabelecidas para análise das questões do ENEM sobre radioatividade.

$\mathrm{Na}$ categoria tipo de resposta, foi avaliado se as alternativas responsivas eram constituídas por números ou textos. Dessa forma, as respostas numéricas caracterizam as questões classificadas como quantitativas, ou seja, que envolvem a manipulação de dados numéricos para encontrar uma solução. As respostas textuais caracterizam as questões classificadas como qualitativas. Segundo Pozo e Gómez (1998) as questões qualitativas envolvem a análise ou interpretação de situações cotidianas e científicas a partir do marco conceitual que proporciona a ciência. Para resolvê-las os estudantes raciocinam teoricamente, sem necessidade de cálculos numéricos e/ou algébricos.

Quanto à categoria contextualização, considerou-se a definição desse termo proposta por Uehara e Núñez (2011). De acordo com essa definição, a contextualização consiste no

\footnotetext{
${ }^{3}$ INEP - http://portal.inep.gov.br/web/enem/edicoes-anteriores/provas-e-gabaritos
} 
contexto no qual o objeto de conhecimento está situado. Ou seja, o tipo de contexto em que o enunciado está inserido (científico, meio ambiente, cotidiano, tecnológico, etc.). As questões que não apresentavam contexto no enunciado foram classificadas como descontextualizadas.

$\mathrm{Na}$ categoria interdisciplinaridade, para analisar as questões, utilizou-se como referencial o estudo de Marcelino-Júnior (2013). De acordo com esse autor, a interdisciplinaridade consiste na integração dos conteúdos de várias disciplinas para compreender e/ou solucionar uma questão. Nesse sentido buscou-se verificar se as questões de radioatividade, apresentavam articulações com outras disciplinas. As questões que se referiam apenas à Química, no âmbito da temática radioatividade, foram classificadas como disciplinares. As questões que envolviam outras disciplinas, além da Química, foram classificadas como interdisciplinares.

No que se refere à categoria recursos visuais, foi avaliado se a questão apresenta: imagens, gráficos, figuras, equações, ou quaisquer elementos visuais, além do texto, que pudessem ser utilizados na compreensão e na resolução.

A categoria eixo cognitivo refere-se aos cinco (05) tipos de enunciado que as questões do ENEM podem apresentar de acordo com a Matriz de Referência (BRASIL, 2009): (i)domínio da linguagem (domínio e uso das linguagens: matemática, artística, Língua Portuguesa, etc.); (ii)- Compreensão de fenômenos (construir e aplicar conceitos das diversas áreas do conhecimento para a compreensão dos fenômenos); (iii)- Resolução de situações-problema (tomada de decisão a partir da seleção, organização, relação e interpretação das informações); (iv) - Construção de argumentação (relacionar informações de forma consistente para construir argumentos); (v)- Elaboração de propostas (elaboração de propostas de intervenção na sociedade a partir dos conhecimentos escolares). A categoria eixo cognitivo permite identificar o tipo de raciocínio que a questão exige para ser solucionada.

Em relação às aplicações da radioatividade, foram avaliadas as possibilidades de inserção dos processos nucleares na Ciência e na Tecnologia. A partir desse sistema de categorias foram obtidos os resultados a seguir.

\section{Resultados e Discussão}

No período de 1998 a 2015 a frequência das questões sobre radioatividade foi irregular. Nos anos 1998, 1999, 2002, 2007, 2008, 2010 e 2011 não houve questões sobre radioatividade nas provas do ENEM, no que se refere à área de Ciências da Natureza e suas Tecnologias. $\bigcirc$ quadro 1, a seguir, mostra o quantitativo de questões e os anos em que elas estiveram presentes, totalizando doze (12) questões.

Quadro 1: Distribuição das questões sobre radioatividade ao longo das edições do ENEM.

\begin{tabular}{|l|l|l|l|l|l|l|l|l|l|l|l|}
\hline Ano & 2000 & 2001 & 2003 & 2004 & 2005 & 2006 & 2009 & 2012 & 2013 & 2014 & 2015 \\
\hline $\begin{array}{l}\text { Número de } \\
\text { questões }\end{array}$ & 02 & 01 & 01 & 01 & 01 & 01 & 01 & 01 & 01 & 01 & 01 \\
\hline
\end{tabular}


De acordo com o quadro 1 , as questões sobre radioatividade estão presentes em pequena quantidade no ENEM, geralmente, apenas uma (01) questão por ano, mesmo em anos em que houve dupla aplicação da prova devido a dificuldades operacionais. Apenas no ano 2000, o tema radioatividade foi contemplado com duas (02) questões. Quanto ao critério referente ao tipo de questão, dez (10) foram classificadas como qualitativas, enquanto que apenas duas (02) questões foram consideradas quantitativas. A seguir um exemplo de questão qualitativa identificada neste estudo.

Quadro 2: Questão do ENEM classificada como qualitativa.

(ENEM - 2014) A elevação da temperatura de rios, lagos e mares diminui a solubilidade de oxigênio, pondo em risco as diversas formas de vida aquática que dependem desse gás. Se essa elevação de temperatura acontece por meios artificiais, dizemos que existe poluição térmica. As usinas nucleares, pela própria natureza do processo de geração de energia, podem causar esse tipo de poluição. Que parte do ciclo de geração de energia das usinas nucleares está associada a esse tipo de poluição?

A fissão do material radioativo.

B condensação do vapor-d'água no final do processo.

C conversão de energia das turbinas pelos geradores.

D aquecimento da água líquida para gerar vapor-d'água.

E lançamento do vapor-d'água sobre as pás das turbinas.

Fonte: Instituto Nacional de Estudos e Pesquisas Educacionais Anísio Teixeira.

Ao longo deste estudo foi observado que houve o predomínio das questões qualitativas sobre o tema radioatividade no ENEM. O exemplo constante no quadro 2 ilustra isso, Nesta questão o estudante precisa estar familiarizado com o funcionamento de um reator de geração de energia nuclear. O caráter conceitual das questões qualitativas analisadas reflete a posição de que a compreensão dos fenômenos radioativos é importante e deve ser valorizada no ensino do tema radioatividade. Além disso, nas poucas questões quantitativas que as provas apresentaram, era necessário entender como ocorrem os processos nucleares para prosseguir com a resolução utilizando os dados numéricos.

Quanto à contextualização, onze (11) questões foram consideradas contextualizadas e apenas uma (01) não apresentou contexto. Esse dado reforça uma recomendação dos Parâmetros Curriculares Nacionais (1999) para que os conteúdos químicos sejam ensinados de forma contextualizada. No que se refere ao contexto adotado nas questões, o meio ambiente esteve presente em cinco (05) enunciados. O contexto cotidiano e o tecnológico foram identificados em duas (02) questões cada. O contexto científico apareceu em apenas uma (01) questão, assim como o contexto tecnológico relativo ao funcionamento de artefatos bélicos.

O contexto ambiental nas questões sobre radioatividade no ENEM envolve conhecimentos químicos e sobre os impactos ambientais causados pelas radiações no meio ambiente. Historicamente, vários acidentes em usinas de energia nuclear (Chernobyl 1986, Fukushima, 2011) ocasionaram mortes e contaminação ambiental devido ao efeito das radiações emitidas a partir de elementos químicos radioativos utilizados nos reatores para gerar energia. Diversos ecossistemas são alterados significativamente quando entram em contato com radiações emitidas por isótopos radioativos. Ar, solo, água, flora e fauna 
sofrem efeitos devastadores quando expostos à radiação do tipo gama. A seguir, o quadro 3 mostra um exemplo de questão contextualizada com o meio ambiente.

Quadro 3: Questão do ENEM classificada como contextualizada com o meio ambiente.

(ENEM - 2013) Na música "Bye, bye, Brasil", de Chico Buarque de Holanda e Roberto Menescal, os versos

"puseram uma usina no mar talvez fique ruim pra pescar"

Poderiam estar se referindo à usina nuclear de Angra dos Reis, no litoral do Estado do Rio de Janeiro. No caso de tratar-se dessa usina, em funcionamento normal, dificuldades para a pesca nas proximidades poderiam ser causadas

(A) pelo aquecimento das águas, utilizadas para refrigeração da usina, que alteraria a fauna marinha.

(B) pela oxidação de equipamentos pesados e por detonações que espantariam os peixes.

(C) pelos rejeitos radioativos lançados continuamente no mar, que provocariam a morte dos peixes.

(D) pela contaminação por metais pesados dos processos de enriquecimento do urânio.

(E) pelo vazamento de lixo atômico colocado em tonéis e lançado ao mar nas vizinhanças da usina.

Fonte: Instituto Nacional de Estudos e Pesquisas Educacionais Anísio Teixeira

Nessa questão são abordados os efeitos causados ao ecossistema marinho causado pela instalação de uma usina de energia nuclear perto do litoral. A preocupação com o meio ambiente é uma questão central nas questões do ENEM relacionadas com o tema radioatividade. Nas edições do ENEM de 2000, 2001, 2003, 2004 e 2005 o tema radioatividade foi abordado juntamente com as questões ambientais. Nas últimas edições desse exame, o aspecto ambiental esteve ausente, embora os debates sobre os fenômenos nucleares sejam constantes nas esferas científicas, ambientais, econômicas e políticas.

A interdisciplinaridade foi identificada entre a Química e a Biologia em sete (07) questões e entre a Química e a Física em apenas uma (01) questão. A interdisciplinaridade envolvendo a Química e a Biologia identificada nas questões sobre radioatividade no ENEM é favorecida pelos aspectos ambientais presentes nos enunciados desse exame. Apenas quatro (04) questões foram classificadas como disciplinares, ou seja, só envolviam conhecimentos de Química. O quadro 4 a seguir é um exemplo de questão interdisciplinar envolvendo a Química e a Biologia. 
Quadro 4: Questão classificada com interdisciplinar envolvendo a Química e a Biologia.

(ENEM - 2000) A energia térmica liberada em processos de fissão nuclear pode ser utilizada na geração de vapor para produzir energia mecânica que, por sua vez, será convertida em energia elétrica. Abaixo está representado um esquema básico de uma usina de energia nuclear.

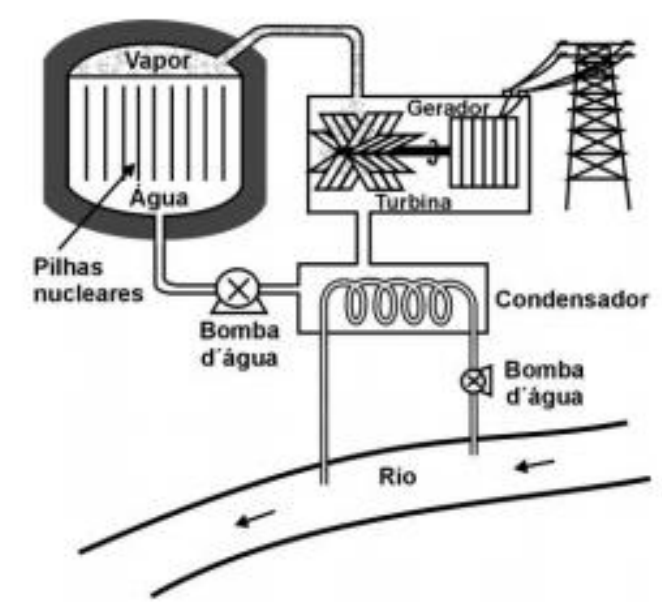

Com relação ao impacto ambiental causado pela poluição térmica no processo de refrigeração da usina nuclear, são feitas as seguintes afirmações:

I o aumento na temperatura reduz, na água do rio, a quantidade de oxigênio nela dissolvido, que é essencial para a vida aquática e para a decomposição da matéria orgânica.

II o aumento da temperatura da água modifica o metabolismo dos peixes.

III o aumento na temperatura da água diminui o crescimento de bactérias e de algas, favorecendo o desenvolvimento da vegetação.

Das afirmativas acima, somente está(ão) correta(s):
(A) I.
(B) II.
(C) III.
(D) I e II.
(E) II e III.

Fonte: Instituto Nacional de Estudos e Pesquisas Educacionais Anísio Teixeira

Os aspectos ambientais nesse enunciado exigem conhecimentos sobre 0 funcionamento de um reator nuclear e sobre o ecossistema aquático. Ao estabelecer relações entre esses conhecimentos abordados em disciplinas diferentes, essa questão sugere que o ensino de radioatividade, visando O ENEM, seja pautado na interdisciplinaridade.

Ao longo de todas as edições do ENEM, as questões sobre radioatividade apresentaram recursos visuais em apenas quatro (04) questões. Duas (02) questões apresentavam apenas uma figura. Enquanto que gráficos e equações só foram identificados em apenas uma (01) questão cada. A seguir, no quadro 5, um exemplo de questão que fez uso de recursos visuais. 
Quadro 5: Questão que apresenta recurso visual do tipo equação.

(ENEM - 2013) Glicose marcada com nuclídeos de carbono-11 é utilizada na medicina para se obter imagens tridimensionais do cérebro, por meio de tomografia de emissão de pósitrons. A desintegração do carbono-11 gera um pósitron, com tempo de meia-vida de 20,4 min, de acordo com a equação da reação nuclear:

$$
{ }_{6}^{11} \mathrm{C} \rightarrow{ }_{5}^{11} \beta+{ }_{0}^{1} e \text { (pósitron) }
$$

A partir da injeção de glicose marcada com esse nuclídeo, o tempo de aquisição de uma imagem de tomografia é de cinco meias-vidas. Considerando que o medicamento contém 1,00 g do carbono11, a massa, em miligramas, do nuclídeo restante, após a aquisição da imagem, é mais próxima de

A 0,200 .

B 0,969

C 9,80 .

D 31,3 .

E 200.

Fonte: Instituto Nacional de Estudos e Pesquisas Educacionais Anísio Teixeira.

Nessa questão é apresentada a equação nuclear que representa a desintegração do radioisótopo ${ }_{6}^{11} \mathrm{C}$. Essa questão foi classificada como quantitativa e o recurso visual é essencial para a compreensão do enunciado e para a resolução. A ausência de recursos visuais nas questões sobre radioatividade no ENEM indica que esse recurso deve ser incorporado, cada vez mais, a fim de contribuir para a compreensão do enunciado e para o processo de resolução das questões.

De acordo com a Matriz de Referência para o ENEM (BRASIL, 2009) existem cinco (05) eixos cognitivos em que as questões são classificadas. $O$ eixo cognitivo relativo à compreensão dos fenômenos foi verificado em sete (07) questões. O eixo referente ao domínio da linguagem foi observado em dois (02) enunciados. Os eixos, resolução de situações-problema, construção de argumentação e elaboração de propostas só foram identificados apenas uma (01) vez cada. Em algumas questões mais de um eixo cognitivo pode ser identificado, contudo, a classificação realizada neste estudo levou em consideração o eixo cognitivo predominante. Nessa categoria, observou-se que as questões sobre radioatividade analisadas contemplam todos os eixos cognitivos previstos na Matriz de Referência para o ENEM (BRASIL, 2009). No entanto, existe o predomínio do eixo referente à compreensão dos fenômenos. O eixo cognitivo referente à compreensão dos fenômenos, presente na maior parte das questões do ENEM sobre radioatividade, aponta para a relevância do aspecto conceitual no ensino dos processos nucleares. Esse aspecto das questões analisadas é importante e chama a atenção para o ensino de radioatividade, visto que, existem muitas concepções alternativas associadas a esse tema (SILVA, et al, 2013).

A seguir, o quadro 6 apresenta uma questão que foi classificada no eixo da compreensão dos fenômenos. 
Quadro 6: Questão relacionada ao eixo da compreensão dos fenômenos.

(ENEM - 2005) Um problema ainda não resolvido da geração nuclear de eletricidade é a destinação dos rejeitos radiativos, o chamado "lixo atômico". Os rejeitos mais ativos ficam por um período em piscinas de aço inoxidável nas próprias usinas antes de ser, como os demais rejeitos, acondicionados em tambores que são dispostos em áreas cercadas ou encerrados em depósitos subterrâneos secos, como antigas minas de sal. A complexidade do problema do lixo atômico, comparativamente a outros lixos com substâncias tóxicas, se deve ao fato de

(A) emitir radiações nocivas, por milhares de anos, em um processo que não tem como ser interrompido artificialmente.

(B) acumular-se em quantidades bem maiores do que o lixo industrial convencional, faltando assim locais para reunir tanto material.

(C) ser constituído de materiais orgânicos que podem contaminar muitas espécies vivas, incluindo os próprios seres humanos.

(D) exalar continuamente gases venenosos, que tornariam o ar irrespirável por milhares de anos.

(E) emitir radiações e gases que podem destruir a camada de ozônio e agravar o efeito estufa.

Fonte: Instituto Nacional de Estudos e Pesquisas Educacionais Anísio Teixeira.

O quadro 6 apresenta uma questão que se refere ao armazenamento de rejeitos radioativos. Essa questão requer conhecimentos sobre o período de desintegração de radioisótopos e sobre sua composição. Além disso, é preciso conhecer as formas de realizar o descarte dos materiais radioativos. A compreensão sobre o decaimento radioativo de radioisótopos é fundamental para resolver esse enunciado. É possível identificar que nessa questão que o foco está na compreensão dos fenômenos nucleares, em especial, na cinética dos processos radioativos.

No que se refere à aplicação da radioatividade, apenas uma (01) questão não apresentou um contexto de utilização de fenômenos nucleares. Em sete (07) questões foi mencionada a produção de energia nuclear. Em três (03) questões foi identificada aplicações da radioatividade na medicina. Em apenas uma (01) questão, a radioatividade foi empregada no contexto dos artefatos bélicos.

A aplicação da radioatividade na produção de energia nuclear enfatizada nas questões do ENEM que foram analisadas, sugere o debate sobre o uso desse tipo de energia na sala de aula. Em muitos países, as usinas nucleares correspondem à maior parte da matriz energética. No Brasil existem duas usinas nucleares em operação no Estado do Rio de Janeiro, as usinas de Angra I e Angra II, porém existem projeções para a instalação de, pelo menos, mais uma usina de energia desse tipo (BRASIL, 2008). A utilização de energia nuclear na matriz energética é fonte de grandes controvérsias entre os especialistas. De acordo com Vichi e Mansor (2009) existem debates intensos sobre o uso da energia nuclear com duas linhas de pensamento distintas, uma delas se dá no sentido da erradicação desse tipo de produção de energia pela possibilidade iminente de acidentes, em outra direção há a defesa da produção de energia nuclear pois não contribui para a produção de gases que geram o efeito estufa, portanto é uma forma menos poluente de geração de energia. Outro aspecto importante nesse debate é o descarte dos resíduos gerados pelas usinas nucleares, esse tipo de material é altamente perigoso e pode contaminar o meio ambiente por muitos anos. 
A seguir o quadro 7 apresenta um exemplo da aplicação da energia nuclear em uma questão do ENEM.

Quadro 7: Questão relacionada à aplicação da radioatividade à geração de energia nuclear.

(ENEM - 2006) O funcionamento de uma usina nucleoelétrica típica baseia-se na liberação de energia resultante da divisão do núcleo de urânio em núcleos de menor massa, processo conhecido como fissão nuclear. Nesse processo, utiliza-se uma mistura de diferentes átomos de urânio, de forma a proporcionar uma concentração de apenas $4 \%$ de material físsil. Em bombas atômicas, são utilizadas concentrações acima de $20 \%$ de urânio físsil, cuja obtenção é trabalhosa, pois, na natureza, predomina o urânio não-físsil. Em grande parte do armamento nuclear hoje existente, utiliza-se, então, como alternativa, o plutônio, material físsil produzido por reações nucleares no interior do reator das usinas nucleoelétricas. Considerando-se essas informações, é correto afirmar que:

A a disponibilidade do urânio na natureza está ameaçada devido à sua utilização em armas nucleares.

B a proibição de se instalarem novas usinas nucleoelétricas não causará impacto na oferta mundial de energia.

C a existência de usinas nucleoelétricas possibilita que um de seus subprodutos seja utilizado como material bélico.

D a obtenção de grandes concentrações de urânio físsil é viabilizada em usinas nucleoelétricas.

E a baixa concentração de urânio físsil em usinas nucleoelétricas impossibilita o desenvolvimento energético.

Fonte: Instituto Nacional de Estudos e Pesquisas Educacionais Anísio Teixeira.

Nessa questão são enfatizados os aspectos técnicos dos radioisótopos necessários para a produção de energia nuclear. Além da aplicação na matriz energética, a radioatividade pode ser utilizada na esterilização de materiais cirúrgicos, diagnóstico de doenças e radioterapia. De acordo com Aquino e Aquino (2012) as aplicações da radioatividade contribuem para sociedade, no sentido de produzir equipamentos e tecnologias que podem auxiliar na melhoria da qualidade de vida.

A partir das discussões realizadas, pode-se identificar algumas características das questões do ENEM referentes ao tema radioatividade:

- A maior parte das questões é do tipo qualitativa;

- Predominam as questões contextualizadas com o meio ambiente;

- A maioria das questões envolve a interdisciplinaridade entre a Química e a Biologia;

- Os recursos visuais (figuras, esquemas, gráficos, tabelas, equações, etc.) são utilizados em poucas questões;

- Compreensão dos fenômenos é o eixo cognitivo mais presente nos enunciados;

- A geração de energia nuclear é a aplicação mais citada nas questões. 


\section{Considerações Finais}

As características das questões obtidas nos resultados desta pesquisa reiteram a importância de um ensino que contemple metodologias diferenciadas em sala de aula pautadas nos dois pilares já preconizados nos Parâmetros Curriculares Nacionais, a saber, a contextualização e a interdisciplinaridade. Também apontam para a importância da compreensão dos conceitos na resolução de problemas em diferentes contextos, ambiental, tecnológico, cotidiano, etc. Além disso, a presença tímida de recursos visuais nas questões analisadas não retrata o que a literatura da área de Ensino de Química vem trazendo sobre a relevância do ensino contemplar os três níveis do conhecimento químico, macroscópico (fenomenológico), microscópico (teórico), representacional (simbólico).

Analisar as questões do ENEM no cenário educacional do Brasil é relevante no sentido de promover reflexões acerca da principal avaliação nacional, voltada para estudantes que estão concluindo o Ensino Médio e para pessoas que já concluíram esse nível de escolaridade. As provas do ENEM são realizadas anualmente e contam com milhões de inscritos que possuem objetivos distintos, tais como: ingressar no Ensino Superior numa instituição pública ou privada, participar de programas sociais de financiamento do Ensino Superior ou ainda obter a certificação de conclusão do Ensino Médio. A importância do ENEM para os estudantes e a abrangência desse exame, são indicadores da necessidade de pesquisar como essa avaliação vem sendo aplicada ao longo dos anos. Nesse sentido, este estudo não esgota a possibilidade de análise das questões, outras pesquisas são necessárias e poderão contribuir sobremaneira para esclarecer as formas de avaliação utilizadas no ENEM.

\section{Referências Bibliográficas}

ANDRÉ, M. E. D. A; LUDKE, M. Pesquisa em Educação: abordagens qualitativas. São Paulo: EPU, 2013.

AQUINO, K. A. S.; AQUINO, F. S. Radioatividade e meio ambiente: os átomos instáveis da natureza. São Paulo: Sociedade Brasileira de Química, 2012.

BOO, H. K. Students' understandings of chemical bonds and the energetic of chemical reactions. Journal of Research in Science Teaching, v. 35, n. 5, p. 569-581, 1998.

BRASIL, Ministério da Educação, Secretaria de Educação Média e Tecnológica. Parâmetros Curriculares Nacionais: Ensino Médio. Parte III Ciências da Natureza, Matemática e suas Tecnologias. Brasília, 1999.

BRASIL, Ministério da Educação, Secretaria de Básica. Orientações Curriculares para o Ensino Médio. Vol. 2. Ciências da Natureza, Matemática e suas Tecnologias. Brasília, 2006.

BRASIL, Ministério de Minas e Energia, Agência Nacional de Energia Elétrica. Atlas de Energia Elétrica do Brasil. Brasília, 2008.

BRASIL. Ministério da Educação e Instituto Nacional de Estudos e Pesquisas Educacionais Anísio Teixeira. Matriz de Referência para o ENEM 2009. Brasília, Distrito Federal, 2009.

GIL, A. C. Como elaborar projetos de pesquisa. São Paulo: Atlas, 2010. 
MARCELINO-JÚNIOR, C. A. C. A Interdisciplinaridade nas questões do ENEM 2009. In: RAMALHO, B. L.; NÚÑEZ, I. B. Aprendendo com o ENEM: Reflexões para melhor se pensar o ensino e a aprendizagem das Ciências Naturais e da Matemática, 2013, Brasília: Liber Libro Editora, 2013.

POZO, J. I,; GÓMEZ, C, M. A. Aprender y enseñar Ciencia. Madrid: Morata, 1998.

RAMALHO, B. L.; NÚÑ̃EZ, I. B. Aprendendo com o ENEM: Reflexões para melhor se pensar o ensino e a aprendizagem das Ciências Naturais e da Matemática, 2013, Brasília: Liber Libro Editora, 2013.

SANTOS, W. L. P.; SCHNETZLER, R. P. Educação em química: compromisso com a cidadania. Ijuí: Unijuí, 2010.

SILVA, F. C. V.; CAMPOS, A. F.; ALMEIDA, M. A. V. Concepções alternativas de licenciandos em Química sobre radioatividade. Experiências em Ensino de Ciências, v. 8, n. 1, p. 87-97, 2013.

SILVA, F. C. V.; ALMEIDA, M. A. V.; CAMPOS, A. F. O trabalho com situação-problema utilizando elementos do ensino por pesquisa: análise das impressões de futuros professores de química. Revista de Ensino de Ciências e Matemática, v. 5, n. 1, p. 37-48, 2014.

TEKIN, B. B.; NAKIBOGLU, C. Identifying students' misconceptions about Nuclear Chemistry. A study of turkish High School students. Journal of Chemical Education, v. 83, n. 11, p. 1712-1718.

UEHARA, F. M. G.; NÚÑ̃EZ, I. B. A contextualização do conteúdo e o uso de situaçõesproblema na prova de Ciências Naturais do ENEM 2009. In: RAMALHO, B. L.; NÚÑEZ, I. B. Aprendendo com o ENEM: Reflexões para melhor se pensar o ensino e a aprendizagem das Ciências Naturais e da Matemática, 2013, Brasília: Liber Libro Editora, 2013.

VASCONCELOS, F. C. G. C.,LEÃO, M. B. C. Utilização de recursos audiovisuais em uma estratégia Flexquest sobre radioatividade. Investigações em Ensino de Ciências, v. 17, n. 1, p. 37-58, 2012.

VICHI, F. M.; MANSOR, M. T. C. Energia, meio ambiente e economia: o Brasil no contexto mundial. Química Nova, v. 32, n. 3, p. 757-767, 2009. 